\title{
Sonic Hedgehog Promotes Rod Photoreceptor Differentiation in Mammalian Retinal Cells In Vitro
}

\author{
Edward M. Levine, Henk Roelink, Jennifer Turner, and Thomas A. Reh \\ Department of Biological Structure, University of Washington, Seattle, Washington 98195
}

The hedgehog gene family encodes secreted proteins important in many developmental patterning events in both vertebrates and invertebrates. In the Drosophila eye disk, hedgehog controls the progression of photoreceptor differentiation in the morphogenetic furrow. To investigate whether hedgehog proteins are also involved in the development of the vertebrate retina at stages of photoreceptor differentiation, we analyzed expression of the three known vertebrate hedgehog genes. We found that Sonic hedgehog and Desert hedgehog are expressed in the developing retina, albeit at very low levels, whereas Indian hedgehog $(I h h)$ is expressed in the developing and mature retinal pigmented epithelium, beginning at embryonic day 13. To determine whether hedgehog proteins have activities on developing retinal cells, we used an in vitro system in which much of retinal histogenesis is recapitulated. $\mathrm{N}$-terminal recombinant Sonic Hedgehog protein (SHH-N) was added to rat retinal cultures for 3-12 $\mathrm{d}$, and the numbers of retinal cells of various phenotypes were analyzed by immunohistochemistry. We found that $\mathrm{SHH}-\mathrm{N}$ caused a transient increase in the number of retinal progenitor cells, and a 2- to 10 -fold increase in the number of photoreceptors differentiating in the cultures when analyzed with three different photoreceptor-specific antigens. In contrast, the numbers of retinal ganglion cells and amacrine cells were similar to those in control cultures. These results show that Hedgehog proteins can regulate mitogenesis and photoreceptor differentiation in the vertebrate retina, and $I h h$ is a candidate factor from the pigmented epithelium to promote retinal progenitor proliferation and photoreceptor differentiation.

Key words: Sonic hedgehog; Indian hedgehog; Desert hedgehog; retina; mitogenesis; differentiation; rod photoreceptor
During retinal development in the vertebrate, there is a well conserved sequential development of the various retinal cell types (for review, see Reh, 1992b). Ganglion cells and horizontal cells are generated first, followed by cone photoreceptor cells and amacrine cells. Rod photoreceptor cells, bipolar cells, and Müller glia develop last. Evidence from in vitro and in vivo cell ablation experiments indicates that factors in the local microenvironment are important in directing the retinal progenitor cells to different fates (Reh and Tully, 1986; Reh, 1987, 1992a; Watanabe and Raff, 1990, 1992; Harris and Messersmith, 1992; Altshuler et al., 1993). In particular, the factors that restrict the onset and rate of photoreceptor differentiation in the rat are known to be limiting in dissociated cell culture, density dependent, and developmentally regulated (Watanabe and Raff, 1990, 1992; Harris and Messersmith, 1992; Reh, 1992a; Altshuler et al., 1993).

Several laboratories are attempting to identify the factors that control retinal progenitor cells to adopt particular cell identities by testing candidate molecules in dissociated cell cultures. Although a number of different molecules have been identified in the developing retina that appear to play some role in retinal cell differentiation (see Discussion), we were interested in determining the effects of the hedgehog family of signaling molecules on

\footnotetext{
Received April 21, 1997; revised May 20, 1997; accepted May 27, 1997.

This work was supported by National Institutes of Health Grant RO1 NS28308 to T.A.R and the Foundation Fighting Blindness. E.M.L. was supported by National Research Service Award EY 66056. We acknowledge the excellent technical assistance of Roger Williams. We also thank the members of the Reh laboratory for helpful discussions and criticisms and appreciate the comments of Drs. Olivia Bermingham-McDonogh, Andrew Davis, and Yvonne Meyer on this manuscript.

Correspondence should be addressed to Thomas A. Reh, Department of Biological Structure, Box 357420, University of Washington, Seattle, WA 98195.

Copyright (C) 1997 Society for Neuroscience $0270-6474 / 97 / 176277-12 \$ 05.00 / 0$
}

mammalian retinal development. These molecules make attractive candidates for regulators of retinal cell differentiation for several reasons. First, in the Drosophila eye disk, hedgehog controls the timing and rate of photoreceptor differentiation at the morphogenetic furrow (Ma et al., 1993; Tabata and Kornberg, 1994; Heberlein et al., 1995). Because vertebrate and Drosophila eye development appear to require many of the same transcription factors, it is plausible that they would require some of the same cell-signaling molecules (for review, see Reh and Cagan, 1994). Second, in vertebrates, members of the Hedgehog family have been shown to act as inducing molecules for particular cell fates in spinal cord and mesencephalon (Roelink et al., 1994; 1995; Ericson et al., 1995; Hynes et al., 1995), and it is likely that these molecules play important roles in the overall patterning of the developing nervous system (Ekker et al., 1995b). Third, in vertebrates, Sonic hedgehog (Shh) expression in the zone of polarizing activity can be induced by retinoic acid (RA) (for review, see Johnson and Tabin, 1995), and recently we have reported that RA can act as a rod photoreceptor inducer in embryonic rat retinal cell cultures (Kelley et al., 1994, 1995).

Several studies have recently demonstrated effects of Shh on early stages of eye development in vertebrates. Several lines of evidence indicate that $S h h$ expressed in the prechordal plate mesoderm establishes the midline in the diencephalon and subdivides the eye field. In zebrafish, Ekker et al. (1995b) found that ectopic expression of hedgehog genes inhibits retinal formation by expanding the pax 2 expression and the optic stalk. In addition, suppression of hedgehog signaling either by a dominant-negative protein kinase A (PKA) expression construct or in the cyclops mutant disrupts the development of the optic stalk (Concordet et al., 1996). A similar result was recently obtained from the ho- 
mozygous deletion of the Shh gene in mice. The development of the optic stalk was severely disrupted in these animals, and consequently the neural retina failed to form (Chiang et al., 1996). Recently, Jensen and Wallace (1997) demonstrated that high concentrations of recombinant N-terminal Shh (SHH-N) (Lee et al., 1994; Fan et al., 1995; Roelink et al., 1995) in embryonic day (E) 18 mouse pellet cultures caused a marked increase in progenitor cell proliferation and general increases in the accumulation of differentiated cell types.

To test the effects of hedgehog proteins in the developing rat retina, we used a dissociated cell culture system that supports both the proliferation of retinal progenitor cells and the differentiation of retinal neurons (Reh and Kljavin, 1989; Anchan et al., 1991; Reh, 1992a,b; Kelley et al., 1994). Previous work in our lab and in others has shown that embryonic and neonatal rat retinal cells cultured at high density, either as cell pellets or on glass coverslips, developed at nearly normal rates (Reh and Kljavin, 1989; Watanabe and Raff, 1990; Anchan et al., 1991; Altshuler et al., 1993; Kelley et al., 1994, 1995). At the time of plating, 70\% of the cells are progenitor cells when dissociated from E18 retina. This is the percentage of cells in the retina at E18 that incorporate $\left[{ }^{3} \mathrm{H}\right]$-thymidine or bromo-deoxyuridine (BrdU) (Taylor and Reh, 1990). Most of these cells also express Mash-1, the mammalian homolog to the Drosophila achaete-scute proneural genes (Jasoni and Reh, 1996). These cells are also immunoreactive for nestin (Anchan and Reh, 1995), an intermediate filament protein present in CNS progenitor cells (Cattaneo and McKay, 1990). Several labs have also shown that most retinal cell types differentiate in these cultures, including ganglion cells, (Anchan et al., 1991), amacrine cells (Anchan et al., 1991; Lillien and Cepko, 1992; Reh, 1992a; Kelley et al., 1994), bipolar cells (Lillien and Cepko, 1992), and both rod and cone photoreceptors (Araki et al., 1987; Reh and Kljavin, 1989; Sparrow et al., 1990; Watanabe and Raff, 1990; Kelley et al., 1995).

In embryonic rat retinal cell cultures treated with low concentrations of recombinant SHH-N, we observed a transient mitogenic effect on retinal progenitors, and a 2- to 10-fold increase in the number of photoreceptors differentiating in the cultures when analyzed with three different photoreceptor-specific antigens. In contrast, the numbers of retinal ganglion cells and amacrine cells were similar to those in control cultures. Thus, SHH-N specifically promotes the generation of photoreceptors in rat retinal cultures.

\section{MATERIALS AND METHODS}

$R N A$ extraction. E12 and E13 eyes, E15, E16, E18, postnatal day (P) 0 , $\mathrm{P} 4$, and $\mathrm{P} 6$ adult retinas, $\mathrm{E} 18, \mathrm{P} 0, \mathrm{P} 4, \mathrm{P} 6$, and adult retinal pigmented epithelium (RPE), and P4 lens and sclera were dissected in HBSS with HEPES. The tissues were homogenized in Trizol (Life TechnologiesBRL, Bethesda MD), and total RNAs were isolated according to the manufacturer's instructions. RNA yields were determined by $A_{260}$ on a Beckman DU-70 Spectrophotometer.

Cloning of hedgehog family members from the neural retina and RPE. Three micrograms of total RNA were reverse-transcribed (RT) with random hexamer primers for $1 \mathrm{hr}$ at $42^{\circ} \mathrm{C}$ in a $20 \mu \mathrm{l}$ reaction containing the following: $50 \mathrm{~mm} \mathrm{KCl}, 20 \mathrm{~mm}$ Tris- $\mathrm{HCl}, \mathrm{pH} 8.3,2.5 \mathrm{~mm} \mathrm{MgCl}, 10$ mM DTT, $0.001 \%$ gelatin, $1 \mathrm{~mm}$ dNTP (Pharmacia, Pleasant Hill, CA), 30 U RNasin (Promega, Madison WI), 100 pmol random hexamers (Pharmacia), and $200 \mathrm{U}$ MoMuLV reverse transcriptase (Life Technologies-BRL). Negative control RT reactions were performed as above but without the addition of reverse transcriptase. Ten microliters of the RT reaction were then amplified for 30 cycles on a Perkin-Elmer thermocycler in a $50 \mu \mathrm{l}$ reaction containing $500 \mathrm{ng}$ primers, $0.2 \mathrm{~mm}$ dNTP 2.5 U Taq polymerase (BRL), and final buffer concentrations of 50 $\mathrm{mm} \mathrm{KCl}, 10 \mathrm{~mm}$ Tris $\mathrm{HCl}, \mathrm{pH} 8.3$, and 1.9-2.3 mM $\mathrm{MgCl}_{2}$. Conserved hedgehog family oligonucleotide primers corresponding to amino acid sequences IFKDEEN (ATHTTYAARGAYGARGARAA) and the reverse compliment of AHIHCSVK (TCRTARTANACCCARTCRAA) were used for PCR amplification. The PCR products were analyzed by Southern blot hybridization and cloned into the pTA vector (Invitrogen, San Diego CA). Random clones were isolated, and DNA was sequenced to verify that we had obtained rat Shh and Desert hedgehog (Dhh) cDNAs. Indian hedgehog (Ihh) clones were isolated from RT-PCR reactions of E18 RPE and identified by DNA sequencing.

Tissue distribution and developmental expression of Shh and Ihh $\mathrm{mR}$ NAs. P4 lens, P4 retina, P4 RPE, P4 sclera, E12 eye, E13 eye, all stages of RPE (1.5 $\mu \mathrm{g}$ of each), and $3 \mu \mathrm{g}$ each of E15, E16, E18, P0, P6, and adult retinal total RNAs were used as templates for RT reactions. RT reactions $(1.5 \mu \mathrm{l})$ were used as templates for the PCR reactions. All PCR reactions were performed as above with the following modifications: 2.5 $\mu \mathrm{Ci}\left[{ }^{32} \mathrm{P}\right]$-dCTP $(3000 \mathrm{Ci} / \mathrm{mmol}), 1.5 \mathrm{~mm} \mathrm{MgCl}_{2}$, and $50 \mathrm{pmol}$ per primer (except Ihh reverse primer at $100 \mathrm{pmol}$ ). Shh PCR reactions were performed as follows: $94^{\circ} \mathrm{C}$ for $3 \mathrm{~min} ; 26$ cycles of $94^{\circ} \mathrm{C}$ for $30 \mathrm{sec}, 56^{\circ} \mathrm{C}$ for $30 \mathrm{sec}$, and $72^{\circ} \mathrm{C}$ for $45 \mathrm{sec}$. The sequences of the Shh specific primers used were CGGCCGATATGAAGGGAAGA (forward primer) and CGGAGTTCTCTGCTTTCACA (reverse primer). Ihh PCR reactions were performed as follows: $94^{\circ} \mathrm{C}$ for $3 \mathrm{~min} ; 26$ cycles of $94^{\circ} \mathrm{C}$ for $30 \mathrm{sec}$, $64^{\circ} \mathrm{C}$ for $30 \mathrm{sec}$, and $72^{\circ} \mathrm{C}$ for $45 \mathrm{sec}$. The sequences of the Ihh specific primers used were CCTCATGACCCAGCGCTGCAAG (forward primer) and GCCGARTGCTCDGACTTGAC (reverse primer). Actin PCR reactions were performed as follows: $94^{\circ} \mathrm{C}$ for $3 \mathrm{~min} ; 15$ cycles of $94^{\circ} \mathrm{C}$ for $30 \mathrm{sec}, 56^{\circ} \mathrm{C}$ for $30 \mathrm{sec}$, and $72^{\circ} \mathrm{C}$ for $45 \mathrm{sec}$. The sequences of the actin specific primers were AAGAGAGGCATCCTGACCCT (forward primer) and TACATGGCTGGGGTGTTGAA (reverse primer). Reaction products were size-resolved by electrophoresis in $5 \%$ native polyacrylamide gels. Gels were fixed, dried, and analyzed by autoradiography (13.5 hr at $-70^{\circ} \mathrm{C}$ with an intensifying screen).

Quantification of Shh expression. Full-length Shh cDNA in pBluescript was linearized, and sense RNA was generated by in vitro transcription. Template DNA was removed with DNase I, and the RNA was extracted with $1: 1$ phenol/chloroform and precipitated in $0.4 \mathrm{M} \mathrm{LiCl}$ and 3 vol of $100 \%$ EtOH. After resuspension of the RNA pellet in $\mathrm{H}_{2} \mathrm{O}$, the RNA concentration was determined by $\mathrm{A}_{260}$. Increasing concentrations of Shh sense RNA $(0,0.3,3$, and $30 \mathrm{pg})$ were added to $3 \mu \mathrm{g}$ aliquots of P10 rat brain RNA and used as templates in RT reactions as above. Shh and actin PCR reactions and subsequent analysis were performed as described above.

Cell culture. Timed pregnant Sprague Dawley rats were obtained from Simonsen Laboratories. E18 pregnant females were killed with $\mathrm{CO}_{2}$, and the embryos were dissected into sterile HBSS with HEPES buffer at $4^{\circ} \mathrm{C}$. Neural retinas were dissected from the embryos and dissociated by mild trituration after a $10-15 \mathrm{~min}$ incubation at $37^{\circ} \mathrm{C}$ in calcium-magnesiumfree saline with trypsin $(0.025 \%)$. Total cell number was determined with a hemacytometer. Cells were plated onto coverslips in 24 -well plates at a density between 200,000 and 500,000 cells per well. Coverslips were coated sequentially with polylysine and Matrigel (1:100 dilution in HBSS; Collaborative Research, Bedford MA). For low density cell survival experiments, cells were plated at 40,000 cells per well onto coverslips coated with a fibrillar collagen gel in a 24-well plate. The fibrillar collagen-coated coverslips were prepared using Vitrogen, according to the manufacturer's specifications (Collagen Corporation). All cultures were maintained at $37^{\circ} \mathrm{C}$ and $5 \% \mathrm{CO}_{2}$ for periods of $2-14 \mathrm{~d}$. The culture medium contained DMEM/F12 (without glutamate or aspartate), 25 $\mu \mathrm{g} / \mathrm{ml}$ insulin, $100 \mu \mathrm{g} / \mathrm{ml}$ transferrin, $60 \mu \mathrm{M}$ putrescine, $30 \mathrm{nM}$ selenium, $20 \mathrm{nM}$ progesterone, $100 \mathrm{U} / \mathrm{ml}$ penicillin, $100 \mu \mathrm{g} / \mathrm{ml}$ streptomycin, $0.05 \mathrm{M}$ HEPES, and 1\% fetal bovine serum (Life Technologies-BRL). One half of the media in each well was changed every $48 \mathrm{hr}$.

SHH-N was added on the first day of culture. Unless indicated, $12 \mathrm{~nm}$ SHH-N protein was the final concentration. To obtain recombinant SHH-N, a cDNA encoding SHH-N (residues 1-198 of rat SHH) (Roelink et al., 1994) was cloned in a baculovirus expression vector (modified from Invitrogen), and SHH-N protein was purified (Porter et al., 1995) from supernatant of viral-infected 5B1-4 (High-Five) cells. Protein concentration was determined by dye binding and comparison using ELISA with Escherichia coli-derived mouse SHH-N (provided by Dr. P. Beachy, Johns Hopkins University).

Determination of cell phenotypes. After culture periods of 2-14 d, coverslips were fixed in $4 \%$ paraformaldehyde for $1 \mathrm{hr}$ to overnight and then rinsed in PBS before processing for immunohistochemistry. In some experiments, the cells in each of the culture wells were dissociated with 
A

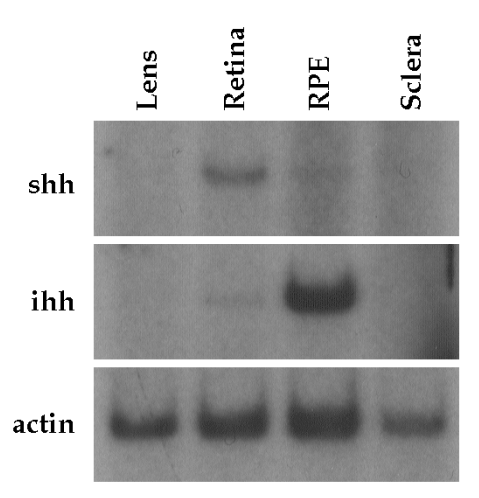

C

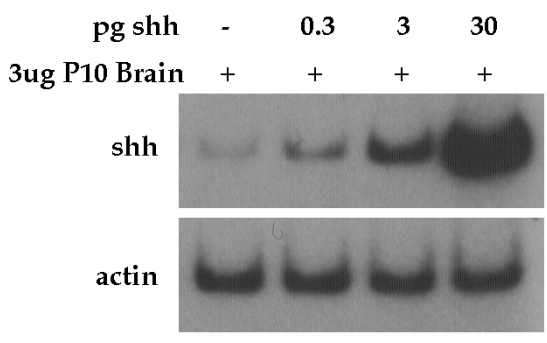

B

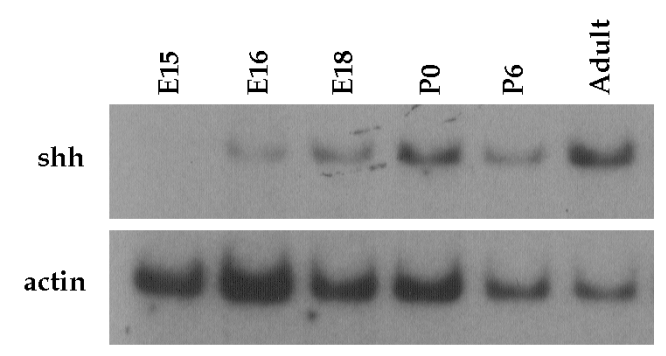

D

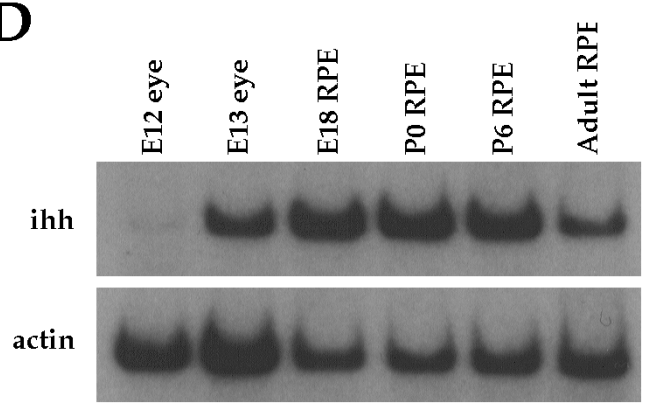

Figure 1. Hedgehog gene expression in the developing rat eye by RT-PCR. $A$, In $\mathrm{P} 4$ ocular tissues, Shh and $I h h$ mRNAs were not detected in lens or sclera. Shh was detected in the retina and a minute quantity was detected in the RPE. Ihh was detected in RPE, and a minute quantity was detected in the retina. $B, S h h$ was first detected in the developing retina at E16 and was detected at all stages of development examined and in the adult. $C$, The amount of $S h h$ expressed in the retina was quantified using serial dilutions $(0.3,3,30 \mathrm{pg})$ of in vitro transcribed full-length Shh RNA mixed with $3 \mu \mathrm{g}$ of P10 rat brain RNA before RT-PCR. In all experiments, actin RT-PCR reactions served as normalization controls. Shh and Ihh PCR reactions were amplified for 26 cycles, and actin PCR reactions were amplified for 15 cycles. Amplification products were not observed when reverse transcriptase was omitted from the reactions. $D$, Ihh was first detected in the eye at E13 and expressed in the RPE at E18 and in all subsequent stages examined, including the adult. trypsin, counted with a hemacytometer, and then allowed to adhere to polylysine-coated coverslips for $2-6 \mathrm{hr}$ before fixation and subsequent immunohistochemistry. To identify specific types of retinal cells in each of the cultures, the coverslips were processed for immunohistochemistry using a previously published protocol (Reh and Kljavin, 1989; Kljavin and Reh, 1991). Primary antibodies used in these experiments were as follows: (1) rod-specific opsin, 4D2 monoclonal antibody from Dr. R. Molday and Dr. D. Hicks, University of British Columbia (Hicks and Barnstable, 1987); (2) recoverin, affinity-purified polyclonal rabbit antisera from Dr. J. Hurley, University of Washington (Dizhoor et al., 1991; Milam et al., 1993); (3) cellular retinoic acid binding protein C1 interphotoreceptor retinal-binding protein (IRBP) monoclonal antibodies from Dr. J. Saari, University of Washington (De Leeuw et al., 1990); (4) nestin monoclonal antibody from the Developmental Hybridoma Bank; and (5) Brn3.0, affinity-purified polyclonal antisera from Dr. E. Turner, University of California San Diego. The Brn3.0 gene encodes a POU domain transcription factor with retinal expression limited to retinal ganglion cells (Turner et al., 1994; Xiang et al., 1995). Primary antibody labeling was detected using fluorosceinated or biotinylated secondary antibodies and peroxidase-conjugated avidin (where appropriate). Labeled cells were viewed on a Zeiss standard compound microscope with Epi-Fluorescent illumination, and the number of labeled cells on each coverslip was quantified in most cases by counting all of the labeled cells in either a vertical or horizontal strip across the entire coverslip. In some of the experiments, where the distribution of the cells was more uniform, the labeled cells in 6-10 random fields were counted.

\section{RESULTS}

\section{Shh, Dhh, and Ihh are expressed in the developing rat eye}

To determine whether hedgehog genes are expressed in the developing rat retina, we amplified cDNAs from total retinal RNA of newborn rats using RT-PCR and hedgehog-specific degenerate oligonucleotide primers. The amplification products were analyzed by Southern blot hybridization using a digoxygenin-labeled oligonucleotide probe internal to the original primer set to verify that the amplification products contained hedgehog cDNAs. The
cDNAs were then cloned into pTA and sequenced. Two previously identified hedgehog genes, Shh (Echelard et al., 1993; Krauss et al., 1993; Riddle et al., 1993; Chang et al., 1994; Roelink et al., 1994) and Dhh (Echelard et al., 1993), were identified. When a similar amplification was performed using the RPE as the source of the RNA, we obtained clones of Ihh but not Shh or Dhh.

We further characterized the expression of Shh in the developing retina and other ocular tissues at various times during eye development using quantitative RT-PCR. In P4 ocular tissues, Shh mRNA was not detected in the lens or sclera but was detected in the retina, and a minute quantity was detected in RPE, which may be attributed to carryover of retinal tissue during tissue dissection (Fig. 1A). Shh was detected in the retina as early as E16 (Fig. $1 B$ ), and its expression continues throughout development and into the adult. When compared with an Shh standard of in vitro transcribed RNA in parallel RT-PCR reactions (Fig. $1 C$ ), we determined that $S h h$ is expressed at $\sim 5-10$ ppm of polyA RNA, suggesting that $S h h$ mRNA is at very low levels in the rat retina.

The RPE is known to be important for retinal development, and so we also further analyzed the expression of Ihh in this tissue by RT-PCR. In P4 ocular tissues, Ihh mRNA was not detected in the lens or sclera but was detected in the RPE, with a minute quantity detected in the retina, which may be attributed to carryover of RPE tissue during the tissue dissection (Fig. $1 A$ ). Ihh is first expressed in the developing RPE at E13 (Fig. 1D), shortly after the onset of differentiation in this layer. The expression of Ihh was maintained throughout eye development and into adult animals. This pattern of expression is consistent with the RPE serving as an extraretinal source of Hedgehog protein for regulating retinal development, in a manner analogous to the way in which the notochord regulates floor plate differentiation in the embryonic spinal cord. 
To determine whether Ihh mRNA in the RPE is more abundant than Shh in the neural retina, we performed a titration for Ihh similar to that of Shh using a mouse Ihh cDNA (kindly provided by Dr. A. MacMahon, Harvard University). The primer sequences match $100 \%$ with this construct, and we found that Ihh is expressed in the RPE within the same order of magnitude as Shh expression in the neural retina (data not shown).

\section{SHH-N stimulates proliferation of retinal progenitor cells}

Previous studies have shown that when dissociated E18 rat retinal cells are cultured at high cell density, the retinal progenitor cells continue to proliferate and generate neurons for up to 1 week in vitro. We and others have previously assayed effects of several mitogenic factors, including TGF- $\alpha$, fibroblast growth factor (FGF), and TGF $\beta$-3 (Anchan et al., 1991; Lillien and Cepko, 1992; Anchan and Reh, 1995). To determine whether SHH-N is mitogenic for retinal progenitors, we analyzed the total number of cells in the SHH-N-treated and control cultures after various periods in vitro (Fig. $2 A$ ). In the SHH-N-treated cultures, there was a noticeable increase in cell number over control cultures after 2 and $4 \mathrm{~d}$ in vitro (DIV). This effect was transient, and by 6 DIV the control cultures had the same number of total cells as the $\mathrm{SHH}-\mathrm{N}$-treated cultures. We also quantified the number of nestin $^{+}$progenitor cells in these cultures (Fig. $2 B$ ). Consistent with the increase in total cell numbers, we found an increase in the number of nestin ${ }^{+}$progenitor cells in the SHH-N-treated cultures over control after 2 and 4 DIV. After 6 DIV, the number of progenitor cells in the SHH-N cultures was nearly the same as that in control cultures.

To further confirm the mitogenic effect of SHH-N, in three separate experiments BrdU was added to the cultures for the last $24 \mathrm{hr}$ at 1-6 DIV. In all experiments, we observed an increase in the number of $\mathrm{BrdU}^{+}$cells in the $\mathrm{SHH}-\mathrm{N}$-treated cultures. At 2 and 4 DIV, SHH-N-treated cultures had an approximately 2.5fold increase in the number of $\mathrm{BrdU}^{+}$cells over controls $(2 \mathrm{DIV}$ : control, 190.3 cells/field; SHH-N, 433.3 cells/field; and 4 DIV: control, 245.7 cells/field; SHH-N, 606.7 cells/field). By 6 DIV, however, there was little difference in the number of $\mathrm{BrdU}^{+}$cells between control and SHH-N-treated cultures (6 DIV: control, 360.3 cells/field; SHH-N, 322.7 cells/field; values at all time points are the means of three random fields; $n=1$ ). Thus, SHH-N stimulates proliferation in retinal progenitor cells but does not sustain it for more than a few days, and the total cell number, the number of nestin ${ }^{+}$cells, and the number of $\mathrm{BrdU}^{+}$cells in the control cultures appear to "catch up" to SHH-N-treated cultures between 6 and 8 DIV.

\section{Sonic Hedgehog selectively promotes the differentiation of photoreceptors in the developing rat retina in vitro}

To test for the activity of Hedgehog proteins on retinal differentiation, we used a previously characterized dissociated cell culture assay. Dissociated E18 retinal cells in culture for 7 DIV under control conditions express antigens and exhibit morphologies characteristic of most retinal cell types. Figure $3 A$ shows cells labeled with the $\mathrm{C} 1$ antibody, which is specific for amacrine cells in the rat retina. The $\mathrm{C}^{+}$cells also have a characteristic morphology in vitro-a large cell body with many processes extending directly from the soma-consistent with their in vivo morphology. Figure $3 C$ shows the immunoreactivity for the protein recoverin, normally expressed in both rod and cone photoreceptors and in a small number of bipolar cells. Note that the morphology of these
A

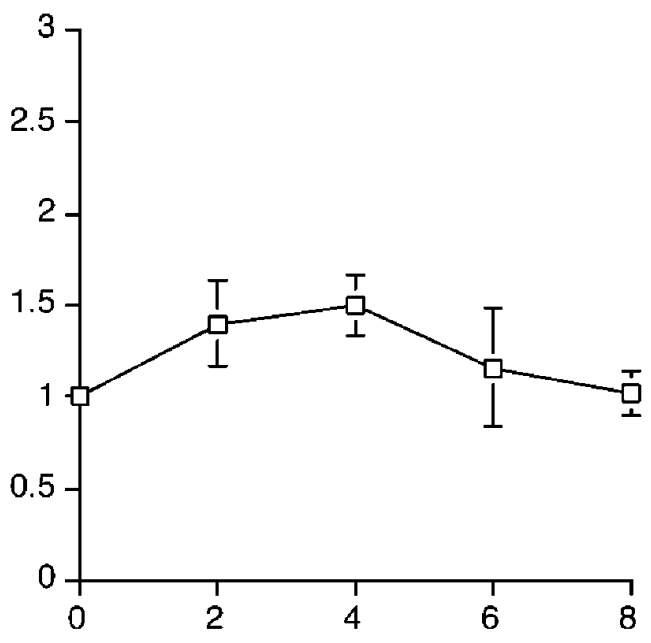

B

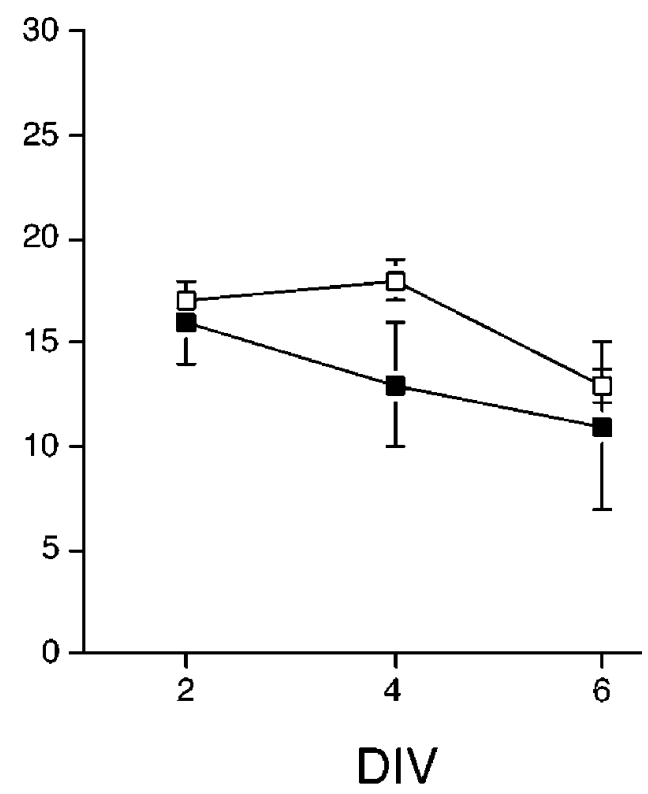

Figure 2. SHH-N effects on progenitor proliferation in vitro. A, Total cells in the wells of SHH-N and control cultures were determined by redissociating the cultures of retinal cells with trypsin and counting a sample on a hemacytometer after 2, 4, and 6 DIV. Shown are the means and SEs of three to five independent experiments expressed as a ratio of the SHH-N-treated cultures to control cultures. There was an initial increase in cell number in the SHH-N-treated cultures after 2 and 4 DIV; however, the difference did not reach statistical significance at any day using an ANOVA and pairwise comparisons. After $6 \mathrm{DIV}$, the ratio between SHH-N and control wells was $1.16 . B$, Nestin ${ }^{+}$progenitor cells were quantified after redissociation and immunostaining. The numbers of nestin $^{+}$progenitor cells were greater in the SHH-N-treated cultures $(\square)$ than in control cultures (ם) after 4 DIV; however, by 6 DIV, the numbers of nestin ${ }^{+}$progenitor cells were the same in SHH-N-treated and control cultures.

cells is different from that of the $\mathrm{C}^{+}$amacrine cells, in that the majority of the recoverin ${ }^{+}$cells have a more simple morphology, more consistent with their photoreceptor identification. Figure $3 E$ shows cells labeled with a rod photoreceptor antibody 4D2 (opsin), a monoclonal antibody raised against rod-specific opsin 

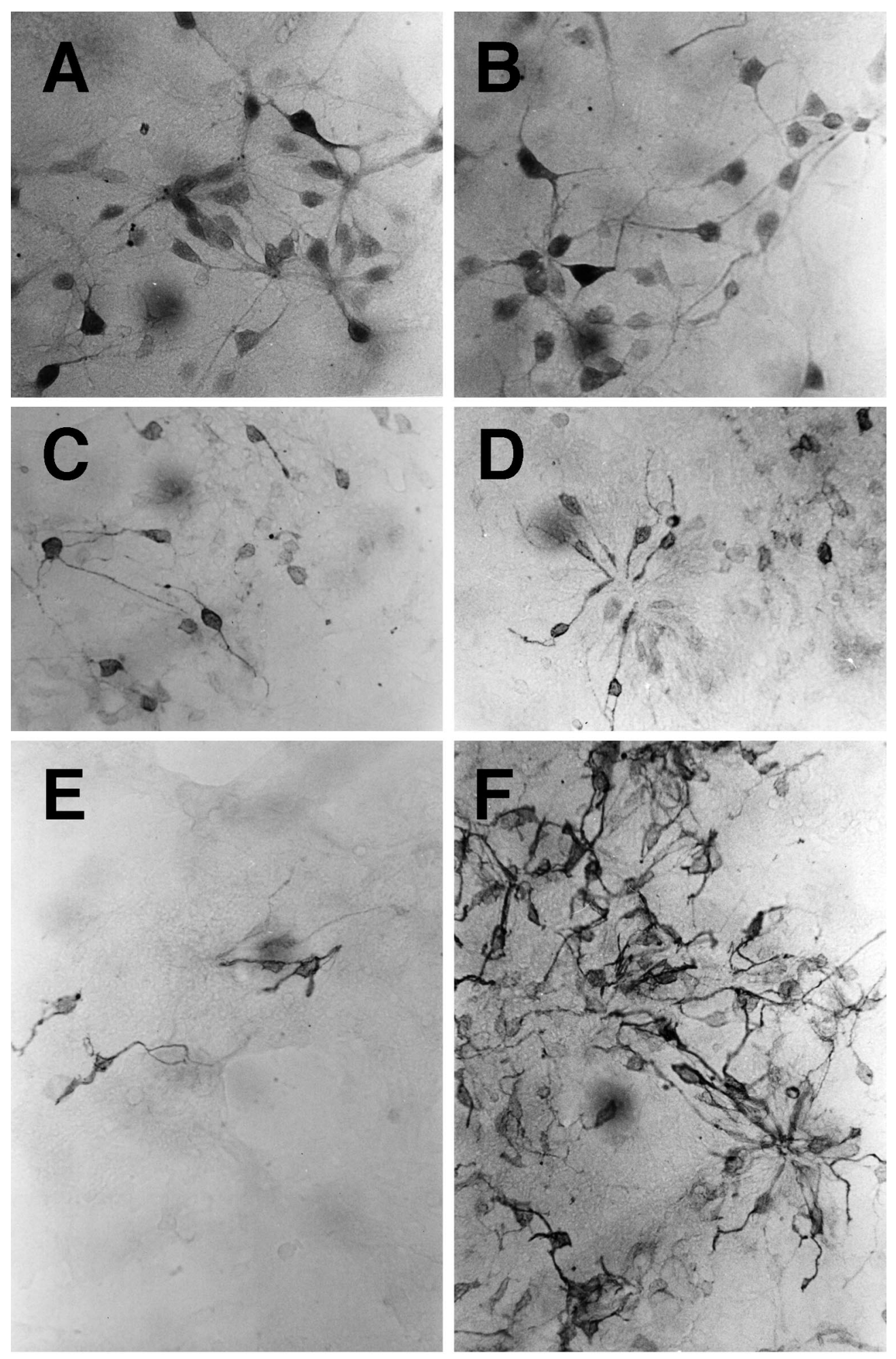

Figure 3. SHH-N selectively promotes rod photoreceptor differentiation in E18 rat retinal progenitor cells in vitro. E18 rat retinal cells were dissociated, plated at high density, and cultured for 7 DIV in the absence ( $A$, $C, E)$ or presence $(B, D, F)$ of SHH-N. Cells in $A$ and $B$ are labeled with the C1 antibody, which labels most amacrine cells in the rat retina. Cells in $C$ and $D$ are labeled with anti-recoverin, a protein present in both rod and cone photoreceptors and the cone bipolar cells. Cells in $E$ and $F$ are labeled with the rod photoreceptor-specific 4D2 antibody (opsin). Although there was some increase in the number of recoverin $^{+}$cells in the SHH-N-treated cultures as compared with the control cultures, the most dramatic effect of SHH-N was on the number of opsin ${ }^{+}$ cells (compare $E$ and $F$ ). protein. Throughout the first week of culture at this density, cells in the cultures are also immunoreactive for ganglion cell antigens, Brn3.0, and neurofilament protein. In addition, previous studies have also shown that these cultures develop other amacrine celland bipolar cell-specific antigens, including HPC-1 (syntaxin) for amacrine cells (Kelley et al., 1994), and PCP-2 and PKC- $\gamma$ for bipolar cells (Kelley et al., 1994). Although several of the retinal cell types are present after 7 DIV under control conditions, a majority of the cells in the cultures incorporate BrdU and express nestin, an intermediate filament protein present in neuronal progenitor cells (Anchan and Reh, 1995). By 14 DIV, however, most cells express antigens characteristic of retinal neurons and photoreceptors (Kelley et al., 1994, 1995). Thus, high density cultures of E18 rat retinal cells support differentiation into all of the retinal cell types after 7-14 DIV.

To determine the effects of SHH on cellular differentiation, 

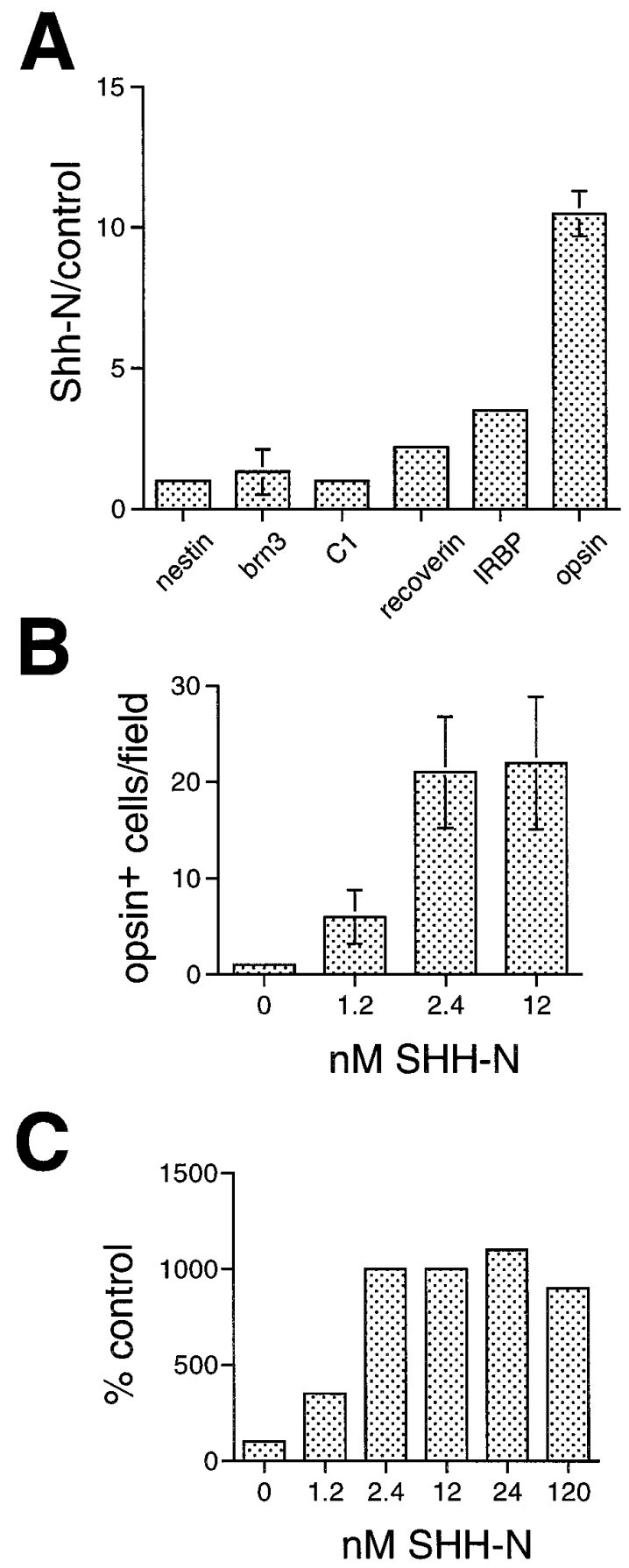

Figure 4. SHH-N promotes expression of photoreceptor specific proteins in retinal cells in vitro. $A$, E18 rat retinal cells were cultured for 6 or 7 DIV, and the numbers of cells expressing several different cell typespecific antigens were quantified. The graph shows the ratios of cells in SHH-N-treated cultures compared with control cultures from three to seven independent experiments (expressed as means and SEs). Rod opsin $^{+}$cells show the greatest increase in the SHH-N-treated cultures ( $\sim 10$-fold) compared with control cultures, but two other photoreceptor antigens, IRBP and recoverin, also show an increase in SHH-N-treated over control cultures. Antigens expressed in other types of retinal neurons (Brn3.0 and C1) and progenitor cells (nestin) were not significantly increased in the SHH-N-treated cultures after 6-7 DIV. $B$, A doseresponse relationship for the effect of SHH-N on photoreceptor differentiation. SHH-N was added to E18 cultures at concentrations ranging from 1.2 to $12 \mathrm{nM}$, and the number of opsin ${ }^{+}$cells was quantified after 6 DIV The number of opsin ${ }^{+}$cells was 20 -fold greater in 2.4 and $12 \mathrm{~nm} \mathrm{SHH}-$ $\mathrm{N}$-treated cultures than control cultures, and fivefold greater when $1.2 \mathrm{nM}$
E18 rat retinal cells were cultured in the presence or absence of recombinant rat SHH-N for 2-14 DIV. SHH-N was added to the medium at a concentration of $\sim 12 \mathrm{nM}$. Figure 3 shows the effects we observed after $7 \mathrm{DIV}$ on $\mathrm{C}^{+}$amacrine cells $(A$ and $B)$, recoverin ${ }^{+}$photoreceptors $(C$ and $D)$, and opsin ${ }^{+}$rod photoreceptors $(E$ and $F)$ in control cultures $(A, C$, and $E)$ and SHH-Ntreated cultures $(B, D$, and $F)$. Although the numbers of amacrine cells were not significantly different between the treated and control cultures, the number of recoverin ${ }^{+}$cells increased moderately in the SHH-N-treated wells, and the number of opsin ${ }^{+}$ cells increased dramatically after SHH-N treatment.

Quantification of cell number for several retinal antigens indicates that SHH-N specifically promotes expression of photoreceptor specific antigens after 7 DIV (Fig. 4A). The results of seven experiments were combined and expressed as a percentage of control. The numbers of $\mathrm{C}^{+}{ }^{+}$amacrine cells, Brn3.0 $0^{+}$ganglion cells, and nestin ${ }^{+}$progenitor cells were not different between the treated and control cultures; however, the number of recoverin ${ }^{+}$ cells increased twofold on average, the number of $\mathrm{IRBP}^{+}$cells increased more than threefold, and the number of opsin ${ }^{+}$cells increased typically 10 -fold. Thus, the numbers of cells immunoreactive for all three photoreceptor antigens increase after SHH-N treatment of E18 rat retinal cells.

A dose-response relationship for the effect of SHH-N on photoreceptor differentiation is shown in Figure $4 B$. SHH-N was added to E18 cultures at concentrations ranging from 1.2 to 12 $\mathrm{nM}$, and the number of opsin ${ }^{+}$cells was quantified after 6 DIV. The addition of 2.4 and $12 \mathrm{nM}$ SHH-N resulted in a 20 -fold increase in the number of opsin ${ }^{+}$cells over control cultures, and a fivefold increase when $1.2 \mathrm{~nm}$ SHH-N was added. The minimal concentration of SHH-N necessary to observe an effect on photoreceptor differentiation is similar to that reported for motor neuron induction in neural tube (Roelink et al., 1994).

In a parallel set of experiments, we assayed for the effects of SHH-N protein added at concentrations of $24 \mathrm{~nm}$ and $120 \mathrm{~nm}$ and cultured for $7 \mathrm{DIV}$. At these concentrations, the ratio of opsin ${ }^{+}$ cells in treated versus untreated was similar to that observed at 12 nм (Fig. 4C). This demonstrates that in high density monolayer cultures, effects of SHH-N protein are saturating by $12 \mathrm{~nm}$.

To determine whether the effects of SHH-N addition on opsin expression were specific to $\mathrm{SHH}-\mathrm{N}$, monoclonal antibody 5E1 raised against SHH-N (Ericson et al., 1996) was added to E18 cultures in the presence and absence of SHH-N protein. We found that $5 \mathrm{E} 1$ supernatant in the presence or absence of SHH-N repressed opsin expression to levels slightly below control values (no $5 \mathrm{E} 1$ or $\mathrm{SHH}-\mathrm{N}$ added) after $8 \mathrm{DIV}$, thereby blocking the effects of exogenous $\mathrm{SHH}-\mathrm{N}$ on rod photoreceptor differentiation (data not shown).

To further characterize the specific effect on photoreceptor differentiation, we analyzed SHH-N-treated and control cultures at 3, 6, and 9 DIV. Figure 5 shows the number of cells immunoreactive for four different antigens as a function of DIV. The number of amacrine cells steadily increased in both the control and treated wells over 9 DIV without significant differences between the control and SHH-N-treated wells (Fig. 5A), indicat-

SHH-N was added. $C$, The dose-response was extended to concentrations of 24 and $120 \mathrm{~nm}$ in a separate experiment. To compare the data represented in $B$ with the higher concentrations of SHH-N, each experimental series is shown as \% control of opsin ${ }^{+}$cells. Control for each experiment was normalized to $100 \%$. 


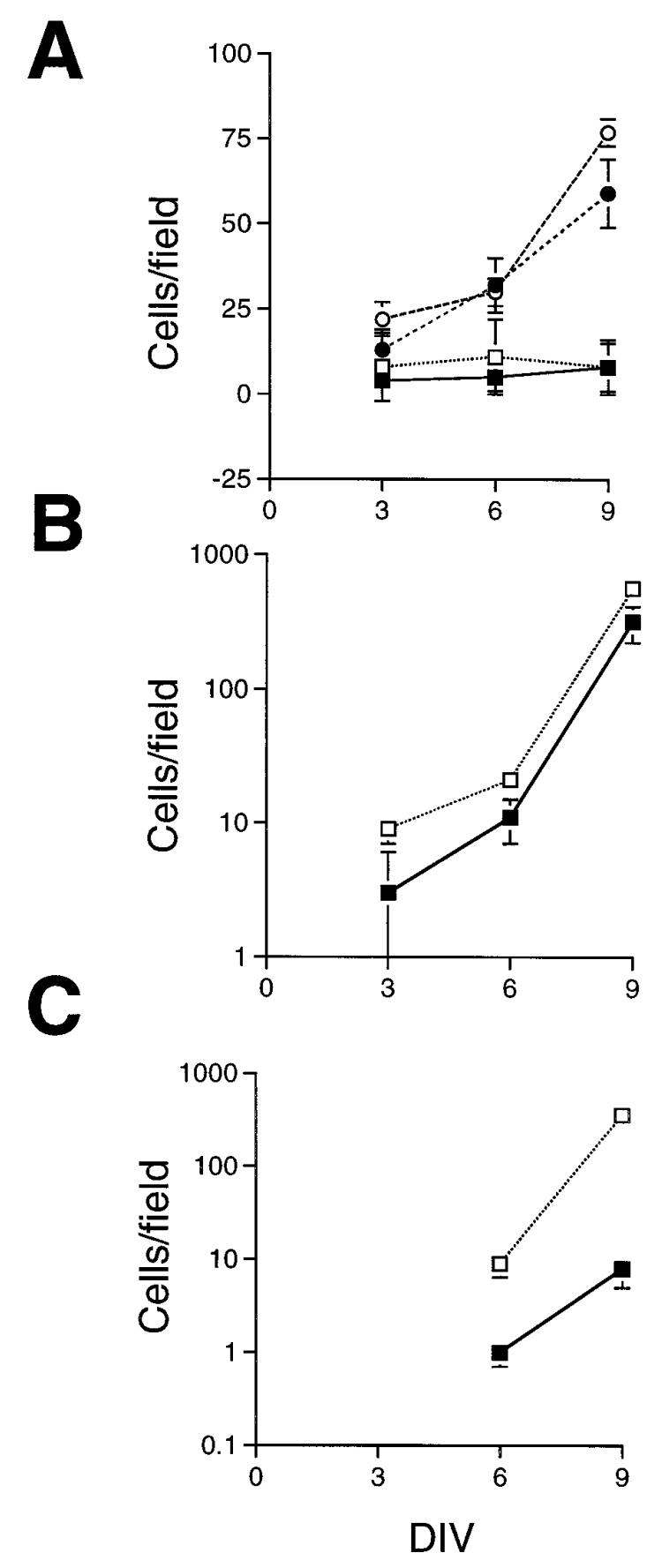

Figure 5. SHH-N selectively promotes rod photoreceptor differentiation. E18 rat retinal cells were cultured at high density for 3, 6, or 9 DIV, and the numbers of cells labeled with one of four different antibodies were quantified by counting labeled cells in six fields at $400 \times$. The means and SEs are plotted as a linear scale in $A$ and as a ${ }^{10} \log$ scale in $B$ and $C . A$, The numbers of amacrine cells, labeled with the $\mathrm{C} 1$ antibody (circles), and ganglion cells, labeled with a Brn3.0 antibody (squares), were not significantly different between the SHH-N-treated cultures (open symbols) and control cultures (solid symbols). B, The number of recoverin ${ }^{+}$cells (expressed in all photoreceptor cells and cone bipolar cells) was greater in the SHH-N-treated cultures (open squares) after 3, 6, and 9 DIV than in control cultures (solid squares). $C$, The number of opsin ${ }^{+}$cells was approximately 10 -fold greater in the SHH-N-treated cultures (open squares) than in control cultures (solid squares) after 6 and 9 DIV. Note: opsin $^{+}$cells were not observed in the six fields counted in either the SHH-N or control cultures after 3 DIV. ing that the continued generation and differentiation of these cells was not affected by SHH-N in the medium. The number of Brn3. $0^{+}$ganglion cells did not change in their numbers over the period of culture (Fig. $5 A$ ), consistent with the fact that by E18, most of the ganglion cells of the retina have already been generated.

That neither ganglion cell nor amacrine cell numbers were affected by the addition of SHH-N to the medium suggested that the effects on photoreceptor numbers were not attributable to an overall survival promoting effect of this factor. In whole retinal explant culture and high density, dissociated retinal cell cultures, retinal ganglion cells are the most susceptible to death, whereas other retinal cell types survive without significant loss in cell numbers (Kelley et al., 1994). That Brn3.0 ${ }^{+}$ganglion cell numbers were not different between $\mathrm{SHH}-\mathrm{N}$-treated and control cultures suggests that $\mathrm{SHH}-\mathrm{N}$ is not acting as a survival factor. It is difficult, however, to adequately assess a small survival effect of a particular factor in high density cultures, because endogenous growth factors known to have trophic effects are synthesized in the retina (for review, see Reh et al., 1995). To directly test the effects of SHH-N on retinal cell survival, we cultured retinal cells in serum-free medium at low density. This sufficiently limits the availability of endogenous factors, and many of the retinal cells undergo apoptotic death within a few days of culture (Bermingham-McDonogh et al., 1996). We found no significant difference in the number of isolated E18 retinal cells after 6 DIV between SHH-N-treated and control cultures (mean and SD of three experiments; SHH-N: $56 \pm 12.5$; control: $46 \pm 7.7$ ).

Adding SHH-N to the retinal cells caused the numbers of recoverin ${ }^{+}$and rod opsin ${ }^{+}$cells to increase in the cultures at all time points examined. Because the number of opsin and recoverin $^{+}$cells per field in both the treated and control wells increased substantially over the culture period, the results are expressed on a ${ }^{10} \mathrm{log}$ scale. Figure $5 B$ shows that there was an approximately twofold increase in the number of recoverin ${ }^{+}$cells in SHH-N-treated cultures over control cultures after 3 DIV (10 cells per field in SHH-N treated vs 5 cells per field in the control), and this difference was maintained after 6 DIV (19 cells per field in SHH-N compared with 9 cells per field in control) and at 9 DIV as well. The numbers of opsin ${ }^{+}$cells were also quantified after 3, 6, and 9 DIV (Fig. 5C). There were no opsin ${ }^{+}$cells in either the control or treated wells after 3 DIV; however, at both 6 and 9 DIV, there were from 10 (6 DIV) to 30 times (9 DIV) more rod opsin ${ }^{+}$cells in the SHH-N-treated cultures than in the control cultures.

In a separate series of experiments, the high density cultures were redissociated (see Materials and Methods) and replated briefly at a lower density before fixation and immunohistochemistry. This allowed us to determine the percentages of the total cells that were immunoreactive for rod opsin and recoverin. The results of these experiments are shown in Figure 6. In the control cultures (Fig. $6 \mathrm{~A}$ ), the percentage of recoverin ${ }^{+}$cells increased from $\sim 10 \%$ of the total after 4 DIV to nearly $40 \%$ after 14 DIV. By contrast, there were no opsin ${ }^{+}$cells after 4 DIV, and the percentage of opsin ${ }^{+}$cells plateau at $\sim 10 \%$ of the total cells, even after 14 DIV. These results suggest that there is a limiting factor for opsin expression even in the high density control cultures. In contrast, addition of SHH-N increased the percentage of total cells expressing opsin to levels nearly identical to that of recoverin, although with a 1-2 d lag. As a result, by 14 DIV the percentage of rod opsin ${ }^{+}$cells reached nearly $40 \%$ of the total cells. 

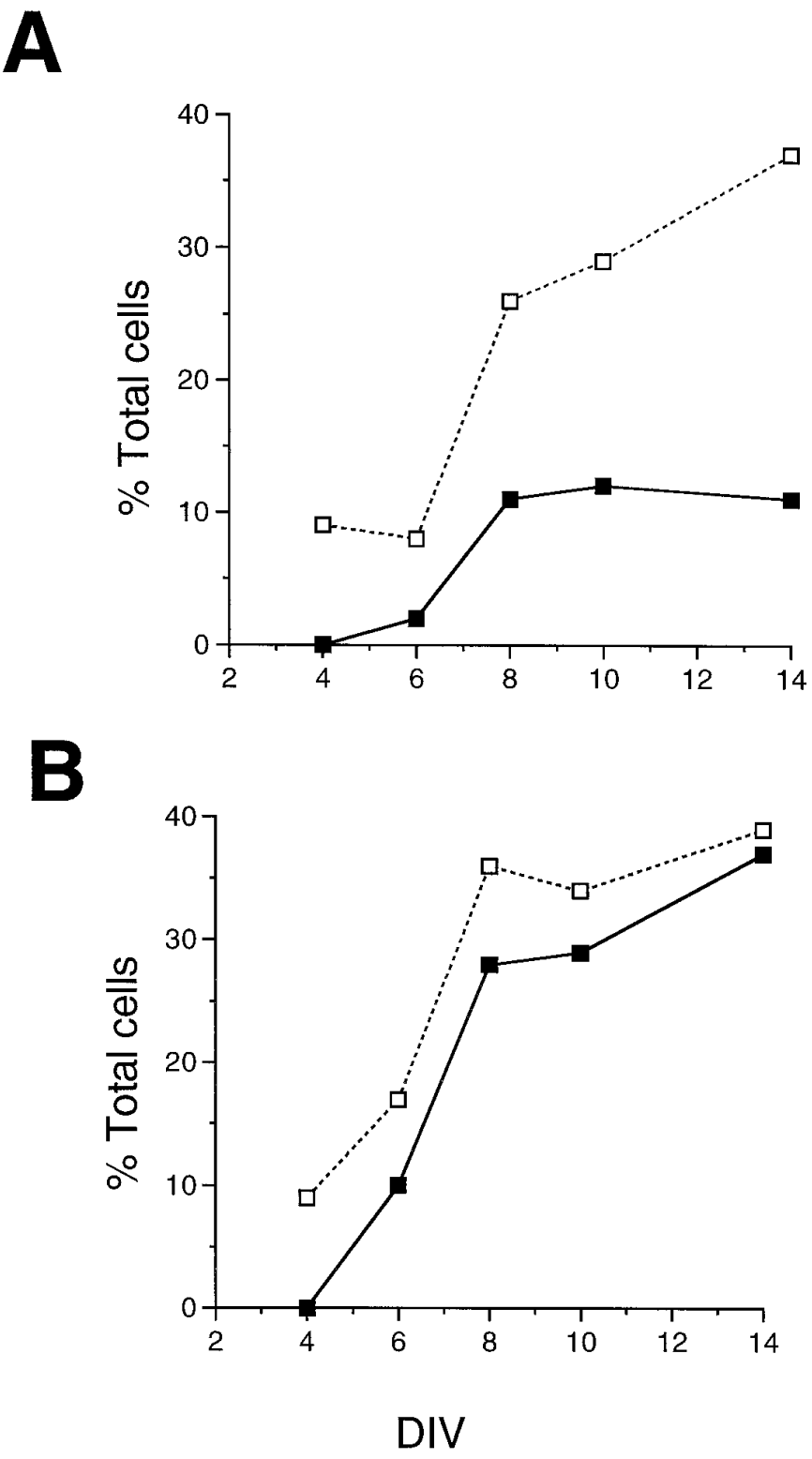

Figure 6. SHH-N promotes opsin expression in cultured rat retinal cells. E18 rat retinal cells were cultured for $4,6,8,10$, and 14 DIV in the presence or absence of SHH-N protein, and the percentages of the total cells in the cultures that expressed rod opsin and recoverin were determined. $A$, In control cultures, the percentage of cells that expressed recoverin increased with time in culture up to $40 \%$; however, the percentages of cells that expressed opsin only reached $10 \%$, even after 14 DIV. $B$, In contrast, the percentages of recoverin ${ }^{+}$and opsin ${ }^{+}$cells increased in parallel in the SHH-N-treated cultures, and both antibodies labeled $\sim 40 \%$ of the retinal cells after 14 DIV.

In some experiments, we double-labeled cultures with opsin and recoverin antibodies at 7 DIV. In previous studies (Kelley et al., 1994, 1995) and in the control cultures of these experiments, virtually all of the opsin ${ }^{+}$cells examined were also recoverin ${ }^{+}$ (data not shown). This finding is consistent with previous in vitro and in vivo data which show that recoverin is expressed before opsin during rat retinal development (Kelley et al., 1994, 1995). Similarly, in the SHH-N-treated cultures, the majority of the cells were either double-labeled with opsin and recoverin (Fig. 7, arrows) or with recoverin alone (Fig. $7 A$, asterisks); however, we identified a subset of opsin ${ }^{+}$cells that were recoverin negative
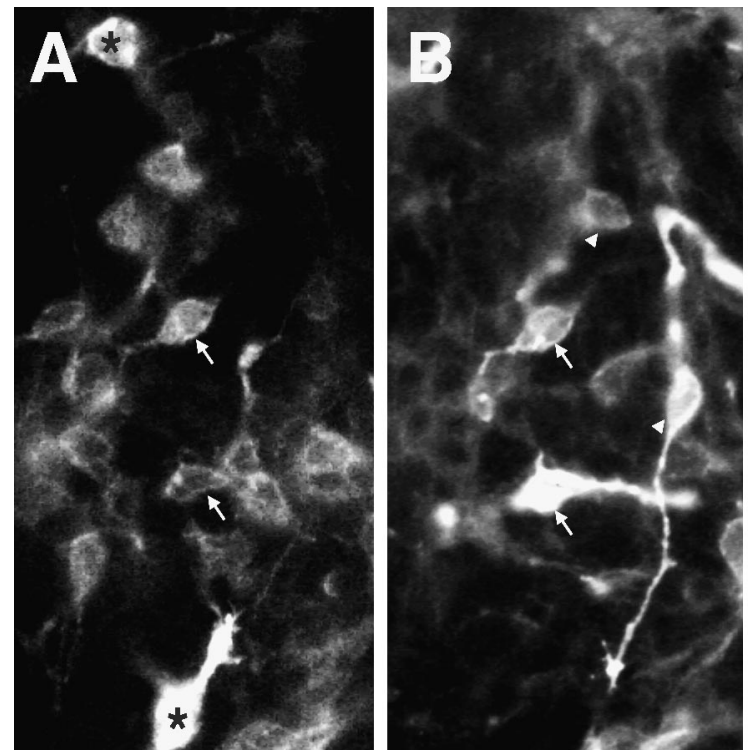

Figure 7. Nearly all recoverin immunoreactive cells also express rod opsin after 2 weeks of culture with SHH-N. E18 rat retinal cells were cultured for 14 DIV in SHH-N-containing media and then labeled with antibody anti-recoverin and a fluorescein-conjugated secondary antibody $(A)$. The same cultures were then labeled with anti-rod opsin and a rhodamine-conjugated secondary antibody $(B)$. As expected, most cells in the field were immunoreactive for both proteins (arrows) or recoverin alone (asterisks). Unexpectedly, a subset of cells were identified that were labeled only with opsin (arrowheads).

(Fig. 7B, arrowheads), suggesting that SHH-N may have direct effects on opsin expression.

\section{DISCUSSION}

\section{Hedgehog proteins in vertebrate eye development}

We found that $S h h, D h h$, and $I h h$ are expressed in the eye during development and in adult rats. Within the eye, $S h h$ and $D h h$ are expressed in the neural retina and $I h h$ is expressed in the RPE throughout much of retinal histogenesis and differentiation. The only other hedgehog family member found to be expressed in the vertebrate eye thus far is the Xenopus Banded hedgehog (Bhh) (Ekker et al., 1995a). To date, a mammalian homolog to Bhh has not been reported. The hedgehog family degenerate primers we used to search for hedgehog genes expressed in the eye failed to detect a $B h h$-like sequence. Although the primer sequences are conserved in $B h h$, the possibility remains that a mammalian Bhh exists and that other more novel hedgehog genes expressed in the eye have yet to be discovered.

Ihh expression has been described previously in cartilage and the developing hindgut (Bitgood and McMahon, 1995). We found that Ihh is also expressed in the RPE very early in ocular development, as early as pigmentation begins. The expression of Ihh is maintained throughout the period of rod photoreceptor differentiation, consistent with the actions of SHH-N in vitro. The restricted expression of $I h h$ to the RPE is interesting in light of previous studies that show a role for this tissue in photoreceptor differentiation (for review, see Grondona et al., 1996). For example, conditioned medium experiments have shown that diff usible factors from the RPE can promote photoreceptor differentiation in vitro (Spoerri et al., 1988).

Jensen and Wallace (1997) reported that $S h h$ is expressed early in retinal histogenesis in a small subset of cells that localize to the 
zone of postmitotic differentiating progenitors cells. In the fully differentiated mouse retina, $S h h$ expression is localized to a small subset of cells in the ganglion cell layer and in the inner tier of the inner nuclear layer. In addition, Patched, a component of the hedgehog receptor complex (Marigo et al., 1996; Stone et al., 1996), is expressed early during retinal development in the neuroblast zone, which in later developmental stages is primarily composed of mitotic progenitors and differentiating rod photoreceptors. In the mature retina, patched is expressed in the middle tier of the inner nuclear layer, which corresponds to expression in bipolar cells and/or Müller glia. These results suggest that progenitor cells and possibly differentiating photoreceptor cells contain a component of the hedgehog signaling pathway that is capable of receiving the hedgehog signal. Furthermore, the localization of $S h h$ to the inner retina and $I h h$ to the RPE suggests that the developing retina is exposed to a combination of hedgehog signals, which may in part contribute to the complexity of the effects observed in vitro.

\section{SHH acts as a mitogen for retinal progenitors}

We have shown that SHH-N has a mitogenic activity on retinal progenitor cells in vitro. This confirms recent findings by Jensen

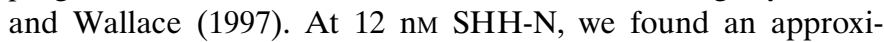
mately 1.5 -fold increase in both total cell number and nestin ${ }^{+}$ cells and more than a twofold increase in $\mathrm{BrdU}^{+}$cells as compared with control cultures after 4 DIV. In pellet cultures of dissociated mouse retinal cells, Jensen and Wallace (1997) found a twofold increase in the percentage of $\mathrm{BrdU}^{+}$cells after 3 DIV at a concentration of $400 \mathrm{~nm}$ SHH-N. Interestingly, we found that by $6 \mathrm{DIV}$ and thereafter, SHH-N-treated and control cultures are nearly identical in their numbers of total cells, nestin ${ }^{+}$cells, and $\mathrm{BrdU}^{+}$cells. Thus, $\mathrm{SHH}-\mathrm{N}$ appears to have a transient mitogenic effect, followed by an increase in cell differentiation, allowing the control wells to "catch up."

In the Drosophila eye disk, Heberlein et al. (1995) found that ectopic hedgehog expression induces string expression, a protein that drives cells in G2 into M-phase. They concluded that "hedgehog induces cell cycle synchronization and arrest in the furrow and cellular proliferation anterior to the furrow." These conclusions are consistent with our findings and suggest that SHH may drive the retinal progenitor cells through a final cell division before promoting their differentiation.

Experiments in Drosophila have implicated PKA in hedgehog signaling in imaginal disks. A current model holds that hedgehog activates decapentaplegic and wingless expression in wing and leg disks by reversing a tonic PKA-mediated inhibition of these genes (Felsenfeld and Kennison, 1995; Jiang and Struhl, 1995; Li et al., 1995; Strutt et al., 1995; Hammerschmidt et al., 1996). Data from vertebrate studies also support this model: the SHH-mediated induction of dopaminergic neurons in the ventral mesencephalon was blocked by increasing the level of PKA activity with forskolin or 8-bromo-cyclic AMP (cAMP) (Hynes et al., 1995). Previous work from our lab has shown that dibuturyl-cAMP, 8-bromocAMP, or forskolin inhibited proliferation in retinal progenitor cells (Taylor and Reh, 1990). Thus, the mitogenic effects of SHH-N are consistent with the Drosophila model of PKA antagonism. We also found that the number of differentiated retinal cells (including opsin ${ }^{+}$cells) increased after treatment of retinal progenitors with PKA activators, indicating that PKA has additional functions in retinal progenitors.

\section{Hedgehog proteins promote photoreceptor differentiation in vitro}

In addition to its effects on cell proliferation, SHH-N also promotes photoreceptor differentiation in vitro. The progressive expression of photoreceptor-specific genes suggests that there are several stages in the differentiation of these cells (Knight and Raymond, 1990). Thymidine birthdating studies demonstrated that rod photoreceptor cells are generated in the rodent retina in both neo- and postnatal periods; however, onset of rod opsin expression occurs 3-4 d after their birthdate (for review, see Reh, $1992 b)$. Because SHH-N stimulates retinal progenitor cell proliferation, it is possible that SHH-N also induces progenitor cells to differentiate into rod photoreceptors. This is analogous to the actions of hedgehog in Drosophila eye disks, in which hedgehog expression also regulates photoreceptor differentiation at the morphogenetic furrow (Jiang and Struhl, 1995; Li et al., 1995; Strutt et al., 1995). It is also possible, however, that hedgehog proteins act later in photoreceptor differentiation. SHH-N treatment results in a subset of cells that express the late differentiation marker, rod-specific opsin, without also expressing recoverin (Fig. 7). Recoverin is normally expressed in photoreceptors before the onset of rod or cone opsins both in vitro and in vivo (Reh, 1992b; Bumsted et al., 1993; Kelley et al., 1994, 1995; Liou et al., 1994; Dorn et al., 1995). These results suggest that although a temporal order exists in the onsets of recoverin expression and opsin expression, this order is not obligatory.

Our results show that SHH-N promoted a two- to threefold increase in the expression of recoverin ${ }^{+}$cells and $\mathrm{IRBP}^{+}$cells, whereas the number of opsin ${ }^{+}$cells increased approximately 10 -fold. Several possibilities exist for these observations. One possibility in considering these differences may lie in the baseline of the numbers of cells expressing these proteins. At early time points (3-7 DIV), the number of recoverin ${ }^{+}$cells and $\mathrm{IRBP}^{+}$ cells is significantly higher than those expressing opsin in the control cultures. Thus, the percentage increase observed in $\mathrm{SHH}$ $\mathrm{N}$-treated cultures is greater for opsin than for recoverin and IRBP when the absolute numbers of cells are compared (Fig. 5). Second, because SHH-N is mitogenic, the increase in recoverin ${ }^{+}$ cells and $\mathrm{IRBP}^{+}$cells may be indirect and attributable to the increase of progenitors in the SHH-N-treated cultures. This is unlikely because the numbers of $\mathrm{C}^{+}$amacrine cells did not increase, and these cells are still being generated in the retina at the time of culture. A third possibility is that the addition of $\mathrm{SHH}-\mathrm{N}$ promotes the proliferation of progenitors at an advanced stage of rod photoreceptor commitment. Although vertebrate retinal progenitors are multipotent (Turner and Cepko, 1987; Holt et al., 1988; Wetts and Fraser, 1988), studies have shown heterogeniety in the responses of retinal progenitors to growth factors and cyclic nucleotide analogs (Taylor and Reh, 1990; Lillien and Cepko, 1992). Furthermore, expression of basic helixloop-helix transcription factors such as Mash I and Cash I are differentially expressed in retinal progenitors at mid to late stages of retinal development in the mouse and chick, respectively (Jasoni et al., 1994; Jasoni and Reh, 1996). Consistent with this possibility is that the increase observed for recoverin- and IRBPexpressing cells could be attributable to expansion of a rodprogenitor pool, and the increase in opsin-expressing cells could be attributable to SHH-N having a later, specific effect on promoting opsin expression on postmitotic differentiating rods. This is analogous to the effects of SHH on motor neuron development, where there is an initial requirement for $\mathrm{SHH}$ just before the final 
mitotic division, as well as a later requirement for differentiation (Ericson et al., 1996).

To determine the nature of the factors that control either the rate or extent of rod differentiation, several groups have tested various candidate molecules known to be present in the developing retina at the appropriate stage of development. To date, the following five factors have been shown to promote rod photoreceptor differentiation: FGF, taurine, RA, S-laminin, and $\mathrm{SHH}$. These factors can be divided into those that act on the progenitor cells and those that act at later stages of differentiation. FGF, taurine, and S-laminin all appear to act on later stages of photoreceptor differentiation rather than directly on the retinal progenitor cells. FGF is more likely to play a survival role for rods than act to promote their generation (Hicks and Courtois, 1992; Bugra et al., 1993; Rakoczy et al., 1993; Gao and Hollyfield, 1995). Another molecule shown to increase the number of rods that differentiate in neonatal rat retinal cultures is taurine (Altshuler et al., 1993). Taurine is present in all cells of the developing retina at a high concentration and is known to be critical for rod survival in adult animals (Hayes et al., 1975; Lake, 1994). There is no direct evidence that taurine acts on the retinal progenitor cells to influence their decision to adopt a rod photoreceptor cell fate; rather, taurine is likely to be critical for the later stages of rod differentiation because it causes an increase in the number of opsin ${ }^{+}$cells when added to cultures many days after cells have undergone their final mitotic division (Altshuler et al., 1993). S-laminin (Hunter et al., 1992) is concentrated in the subretinal space and is also likely to be more important in the later aspects of photoreceptor differentiation, because mice with targeted disruption of the S-laminin gene apparently have a normal numbers of rods, but their outer segments are severely disrupted (Libby et al., 1995).

We reported that RA acts on retinal progenitor cells to promote their differentiation as rod photoreceptor cells (Kelley et al., 1994). Treatment of rat retinal cell cultures with either all-trans or 9-cis RA causes BrdU-labeled progenitor cells to choose the rod photoreceptor cell fate instead of the amacrine cell fate (Kelley et al., 1994). Thus, RA acts at a very early stage in rod photoreceptor genesis. More recently, we have shown that all-trans RA has precisely the same effect in vivo: injection of pregnant rats with all-trans RA causes an increase in the number of rod photoreceptor cells in the retina and a corresponding decline in amacrine cells (Kelley et al., 1995). Exogenous RA treatment also causes an increase in the number of rod photoreceptors in zebrafish retina (Hyatt et al., 1995), suggesting that RA may have an evolutionary conserved role in rod photoreceptor generation.

The relationship between $\mathrm{SHH}$ and other factors known to promote the rod photoreceptor cell fate is complex. SHH-N is mitogenic for retinal progenitor cells and also promotes the differentiation of rod photoreceptors. Because RA does not act as a mitogen for retinal progenitor cells (Kelley et al., 1994), it is unlikely that $\mathrm{SHH}$ acts only to increase RA production or action in the retina. Thus, it is possible that the two factors act through different mechanisms. In the developing limb bud of the chick, SHH and RA have been shown to have partly overlapping effects (Helms et al., 1994). One possible explanation is that $\mathrm{SHH}$ and RA act for short- and long-range patterning, respectively. Indeed, it is likely that the complex overlapping mosaics of the various retinal cell types require several layers of patterning mechanisms. In this later function, $\mathrm{SHH}$ may act with taurine to regulate the further differentiation of the rod photoreceptor cells and potentially regulate the levels of opsin expression in mature retina.

An interesting difference between this study and that of Jensen and Wallace (1997) are the effects of SHH-N on retinal differentiation. We observed significant and specific increases in the numbers of rod photoreceptors at all concentrations of SHH-N tested (1.2-120 nM). By contrast, Jensen and Wallace (1997) did not observe significant increases in any differentiated cell type at medium concentrations of SHH-N (35 nM); however, 1.5- to twofold increases in retinal neurons were observed at higher concentrations (70 and $190 \mathrm{~nm}$ ). The most significant effect they observed was a twofold and fourfold increase in the number of Müller glia at 70 and $190 \mathrm{~nm}$ SHH-N, respectively. One possible reason for the differences observed between our findings and that of Jensen and Wallace (1997) may be the different concentrations of SHH-N that are used. It is unlikely, however, that concentrations of SHH-N alone can explain the difference, because we observed significant increases in the number of opsin ${ }^{+}$cells at $120 \mathrm{~nm}$ SHH-N (a concentration that overlaps with their concentration range). The lack of a specific increase in rod cell number observed by Jensen and Wallace (1997) may be explained by the different culture system used. Because pellet cultures are the highest density cultures possible for dissociated retinal cells, rodinhibitory factors produced by neighboring cells would be in high
Figure 8. Model for Hedgehog action in the retina. Ihh is secreted by the RPE into the intraretinal matrix, and Shh is expressed in cells occupying the inner retina, promoting the mitogenesis of progenitors at the ventricular surface and the differentiation of rods in the developing outer nuclear layer. Cell types such as amacrine cells and ganglion cells occupy the inner half of the retina and are not receptive to Shh signaling.

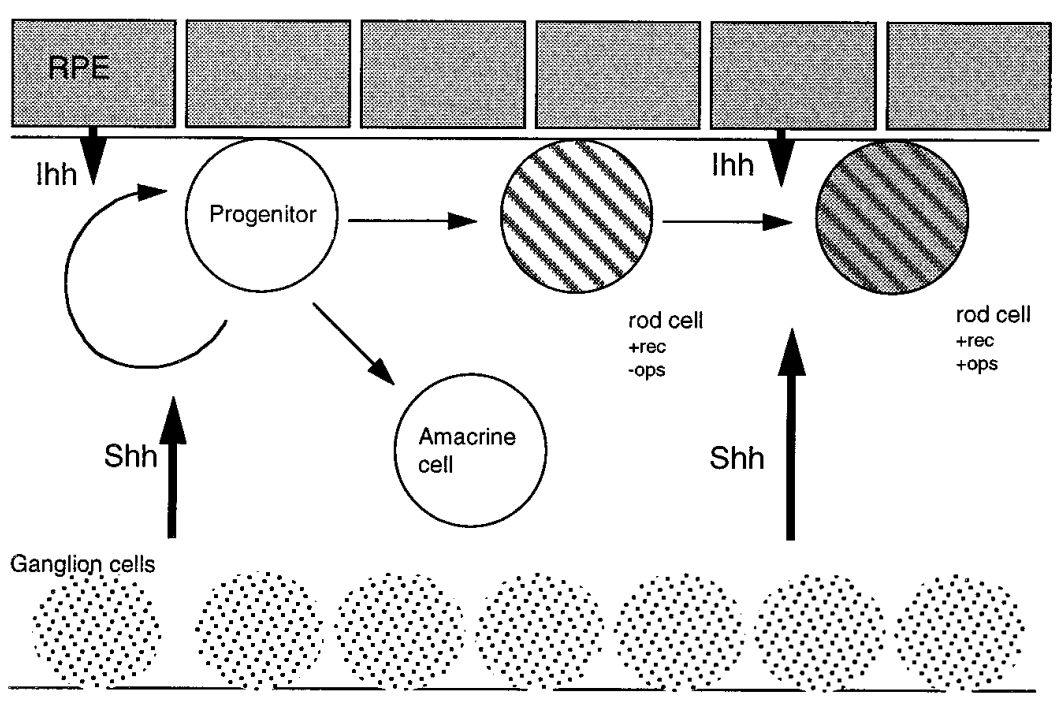


concentration, even in comparison to high density monolayer cultures. Possible rod-inhibitory factors are CNTF and bFGF. CNTF has been shown to be inhibitory for rod photoreceptor differentiation and is produced by the mammalian retina (Kirsch et al., 1996; Ezzeddine et al., 1997). FGF is produced by the retina (Rakoczy et al., 1993) and has been shown to have effects on proliferation and differentiation of the retina (Lillien and Cepko, 1992; Pittack et al., 1997). We observed in E18 high density monolayer cultures that the addition of bFGF $(10 \mathrm{ng} / \mathrm{ml})$ inhibits rod differentiation. Furthermore, repression of rod differentiation is observed with bFGF even in the presence of $12 \mathrm{nM}$ SHH-N (E. M. Levine and T. A. Reh, unpublished observations). Thus, it is likely that in pellet cultures, rod differentiation is repressed because of locally high concentrations of a factor such as CNTF or bFGF, and that this repression is partially relieved at very high concentrations of SHH-N, allowing for increases in cellular differentiation.

We propose the following model for the role of hedgehog in retinal development (Fig. 8). As the pigmented epithelial cells develop during ocular morphogenesis, they release IHH into the intraretinal matrix between the RPE and the developing neural retina. The $\mathrm{IHH}$ acts on the retinal progenitor cells to stimulate their mitosis and on the newly postmitotic rod photoreceptors to stimulate their further differentiation. In this way, an extraretinal source of hedgehog regulates retinal differentiation in a manner analogous to the way in which the notochord regulates floor plate differentiation in the embryonic spinal cord. Consistent with this model is the observation that the processes that $\mathrm{SHH}-\mathrm{N}$ promote in vitro occur at the surface of the retina closest to the RPE in vivo. Furthermore, $S h h$ is expressed in the inner layers of the neural retina. Thus, two putative sources of Hedgehog proteins are present in the developing retina in close proximity to the cells that are responsive to Hedgehog signals, namely, progenitors and developing rod photoreceptors.

\section{REFERENCES}

Altshuler D, Lo-Turco JJ, Rush J, Cepko C (1993) Taurine promotes the differentiation of a vertebrate retinal cell type in vitro. Development 119:1317-1328.

Anchan RM, Reh TA (1995) Transforming growth factor-beta-3 is mitogenic for rat retinal progenitor cells in vitro. J Neurobiol 28:133-145.

Anchan R, Angello J, Balliet A, Walker M, Reh TA (1991) EGF and TGF stimulate retinal germinal neuroepithelial proliferation. Neuron $6: 1-20$.

Araki M, Iiada Y, Taketami S, Watanabe M, Ohta K, Saito J (1987) Characterization of photoreceptor cell differentiation in the rat retinal cell culture. Dev Biol 124:239-247.

Bermingham-McDonogh O, McCabe K, Reh TA (1996) GGF/neuregulins promote neuronal survival and neurite outgrowth in rat retinal cells in vitro. Development 122:1427-1438.

Bitgood MJ, McMahon AP (1995) Hedgehog and Bmp genes are coexpressed at many diverse sites of cell-cell interaction in the mouse embryo. Dev Biol 172:126-138.

Bugra K, Oliver L, Jacquemin E, Laurent M, Courtois Y, Hicks D (1993) Acidic fibroblast growth factor is expressed abundantly by photoreceptors within the developing and mature rat retina. Eur $\mathbf{J}$ Neurosci [Erratum (1994) 6:1062] 5:1586-1595.

Bumsted K, Hendrickson A, Erickson A, Szel A (1993) Immunocytochemical development of cone opsins in Macaca monkey retina. Soc Neurosci Abstr 19:52

Cattaneo E, McKay R (1990) Proliferation and differentiation of neuronal stem cells regulated by nerve growth factor. Nature 347:762-765.

Chang DT, Lopez A, von Kesseler DP, Chiang C, Simandl BK, Renbin Z, Seldin MF, Fallon JF, Beachy PA (1994) Products, genetic linkage and limb patterning activity of a murine hedgehog gene. Development 120:3339-3353.

Chiang C, Litingtung Y, Lee E, Young KE, Corden JL, Westphal H,
Beachy PA (1996) Cyclopia and defective axial patterning in mice lacking sonic hedgehog gene function. Nature 383:407-413.

Concordet JP, Lewis KE, Moore JW, Goodrich LV, Johnson RL, Scott MP, Ingham PW (1996) Spatial regulation of a zebrafish patched homologue reflects the roles of sonic hedgehog and protein kinase A in neural tube and somite patterning. Development 122:2835-2846.

De Leeuw AM, Gaur VP, Saari JC, Milam AH (1990) Immunolocalization of cellular retinol-, retinaldehyde- and retinoic acid-binding proteins in rat retina during pre- and postnatal development. J Neurocytol 19:253-264.

Dizhoor AM, Ray S, Kumar S, Niemi G, Spencer M, Brolley D, Walsh KA, Philipov PP, Hurley JB, Stryer L (1991) Recoverin: a calcium sensitive activator of retinal rod guanylate cyclase. Science 251:915-918.

Dorn GM, Hendrickson LE, Hendrickson A (1995) The appearance of rod opsin during monkey retinal development. Invest Ophthalmol Visual Sci 36:2634-2651.

Echelard Y, Epstein DJ, St-Jacques B, Shen L, Mohler J, McMahon JA, McMahon AP (1993) Sonic hedgehog, a member of a family of putative signaling molecules, is implicated in the regulation of CNS polarity. Cell 75:1417-1430.

Ekker SC, McGrew LL, Lai C-J, Lee JJ, von Kessler DP, Moon RT, Beachy PA (1995a) Distinct expression and shared activities of members of the hedgehog gene family of Xenopus laevis. Development 121:2337-2347.

Ekker SC, Ungar AR, Greenstein P, von-Kessler DP, Porter JA, Moon RT, Beachy PA (1995b) Patterning activities of vertebrate hedgehog proteins in the developing eye and brain. Curr Biol 5:944-955.

Ericson J, Muhr J, Placzek M, Lints T, Jessell TM, Edlund T (1995) Sonic hedgehog induces the differentiation of ventral forebrain neurons: a common signal for ventral patterning within the neural tube. Cell [Erratum (1995) 82:165] 81:747-756.

Ericson J, Morton S, Kawakami A, Roelink H, Jessell TM (1996) Two critical periods of long-range sonic hedgehog signalling required for the specification of motor neuron identity. Cell 87:661-673.

Ezzeddine ZD, Yang X, DeChiara T, Yancopoulos G, Cepko CL (1997) Postmitotic cells fated to become rod photoreceptors can be respecified by CNTF treatment of the retina. Development 124:1055-1067.

Fan CM, Porter JA, Chiang C, Chang DT, Beachy PA, Tessier-Lavigne M (1995) Long-range sclerotome induction by sonic hedgehog: direct role of the amino-terminal cleavage product and modulation by the cyclic AMP signaling pathway. Cell 81:457-465.

Felsenfeld AL, Kennison JA (1995) Positional signaling by hedgehog in Drosophila imaginal disc development. Development 121:1-10.

Gao H, Hollyfield JG (1995) Basic fibroblast growth factor in retinal development: differential levels of bFGF expression and content in normal and retinal degeneration $(r d)$ mutant mice. Dev Biol 169:168-184.

Grondona JM, Kastner P, Gansmuller A, Decimo D, Chambon P (1996) Retinal dysplasia and degeneration in $\operatorname{RAR} \beta 2 / \mathrm{RAR} \gamma 2$ compound mutant mice. Development 122:2173-2188.

Hammerschmidt M, Bitgood MJ, McMahon AP (1996) Protein kinase A is a common negative regulator of Hedgehog signaling in the vertebrate embryo. Genes Dev 10:647-658.

Harris WA, Messersmith SL (1992) Two cellular inductions involved in photoreceptor determination in the Xenopus retina. Neuron 9:357-372.

Hayes KC, Carey RE, Schmidt SY (1975) Retinal degeneration associated with taurine deficiency in the cat. Science 188:949-951.

Heberlein U, Singh CM, Luk AY, Donohoe TJ (1995) Growth and differentiation in the Drosophila eye coordinated by hedgehog. Nature 373:709-711.

Helms J, Thaller C, Eichele G (1994) Relationship between retinoic acid and sonic hedgehog, two polarizing signals in the chick wing bud. Development 120:3267-3274.

Hicks D, Barnstable CJ (1987) Different monoclonal antibodies reveal different binding patterns on developing and adult retina. J Histochem Cytochem 35:1317-1328.

Hicks D, Courtois Y (1992) Fibroblast growth factor stimulates photoreceptor differentiation in vitro. J Neurosci 12:2022-2033.

Holt CE, Bertsch TW, Ellis HM, Harris WA (1988) Cellular determination in the Xenopus retina is independent of lineage and birth date. Neuron 1:15-26.

Hunter DD, Murphy MD, Olsson CV, Brunken WJ (1992) S-laminin expression in adult and developing retinae: a potential cue for photoreceptor morphogenesis. Neuron 8:399-413. 
Hyatt GA, Schmitt EA, Dowling JE (1995) Retinoic acid induces the expansion of rod photoreceptors in the developing zebrafish retina. Soc Neurosci Abstr 21:611.10.

Hynes M, Porter JA, Chiang C, Chang D, Tessier-Lavigne M, Beachy PA, Rosenthal A (1995) Induction of midbrain dopaminergic neurons by Sonic hedgehog. Neuron 15:35-44.

Jasoni CL, Reh TA (1996) Temporal and spatial pattern of MASH-1 expression in the developing rat retina demonstrates progenitor cell heterogeneity. J Comp Neurol 368:1-10.

Jasoni CL, Walker MB, Morris MD, Reh TA (1994) A chicken achaetescute homolog (CASH-1) is expressed in a temporally and spatially discrete manner in the developing nervous system. Development 120:769-783.

Jensen AM, Wallace VA (1997) Expression of Sonic hedgehog and its putative role as a precursor cell mitogen in the developing mouse retina. Development 124:363-371.

Jiang J, Struhl G (1995) Protein kinase A and hedgehog signaling in Drosophila limb development. Cell 80:563-572.

Johnson RL, Tabin C (1995) The long and short of hedgehog signaling. Cell 81:313-316.

Kelley MW, Turner JK, Reh TA (1994) Retinoic acid promotes differentiation of photoreceptors in vitro. Development 120:2091-2102.

Kelley MW, Turner JK, Reh TA (1995) Ligands of steroid/thyroid receptors induce cone photoreceptors in vertebrate retina. Development 121:3777-3785.

Kirsch M, Fuhrmann S, Wiese A, Hofmann HD (1996) CNTF exerts opposite effects on in vitro development of rat and chick photoreceptors. NeuroReport 7:697-700.

Kljavin IJ, Reh TA (1991) Müller cells are a preferred substrate for in vitro neurite extension by rod photoreceptors. J Neurosci 11:2985-2994.

Knight JK, Raymond PA (1990) Time course of opsin expression in developing rod photoreceptors. Development 110:1115-1120.

Krauss S, Concordet JP, Ingham PW (1993) A functionally conserved homolog of the Drosophila segment polarity gene hedgehog is expressed in tissues with polarizing activity in zebrafish embryos. Cell 75:1431-1444.

Lake N (1994) Taurine and GABA in the rat retina during postnatal development. Vis Neurosci 11:253-260.

Lee JJ, Ekker SC, von Kessler D, Porter JA, Sun BI, Beachy PA (1994) Autoproteolysis in hedgehog protein biogenesis. Science 266:1528-1537.

Li W, Ohlmeyer JT, Lane ME, Kalderon D (1995) Function of protein kinase A in hedgehog signal transduction and Drosophila imaginal disc development. Cell 80:553-562.

Libby RT, Hunter DD, Merlie JP, Sanes JR, Brunken WJ (1995) Characterization of developing mouse retinae lacking S-laminin/laminin $\beta 2$. Soc Neurosci Abstr 21:21.11.

Lillien L, Cepko C (1992) Control of proliferation in the retina: temporal changes in responsiveness to FGF and TGF. Development 115:253-266.

Liou GI, Wang M, Matragoon S (1994) Timing of interphotoreceptor retinoid-binding protein (IRBP) gene expression and hypomethylation in developing mouse retina. Dev Biol 161:345-356.

Ma C, Zhou Y, Beachy PA, Moses K (1993) The segment polarity gene hedgehog is required for progression of the morphogenetic furrow in the developing Drosophila eye. Cell 75:927-938.

Marigo V, Davey RA, Zuo Y, Cunningham JM, Tabin CJ (1996) Biochemical evidence that Patched is the hedgehog receptor. Nature 384:176-179.

Milam AH, Dacey DM, Dizhoor AM (1993) Recoverin immunoreactivity in mammalian cone bipolar cells. Vis Neurosci 10:1-12.

Pittack C, Grunwald GB, Reh TA (1997) Fibroblast growth factors are necessary for neural retina but not pigmented epithelium differentiation in chick embryos. Development 124:805-816.

Porter JA, von Kessler DP, Ekker SC, Young KE, Lee JJ, Moses K, Beachy PA (1995) The product of hedgehog autoproteolytic cleavage active in local and long-range signalling. Nature 374:363-366.

Rakoczy PE, Humphrey MF, Cavaney DM, Chu Y, Constable IJ (1993)
Expression of basic fibroblast growth factor and its receptor in the retina of Royal College of Surgeons rats: a comparative study. Invest Ophthalmol Vis Sci 34:1845-1852.

Reh TA (1987) Cell-specific regulation of neuronal production in the larval frog retina. J Neurosci 7:3317-3324.

Reh TA (1992a) Cellular interactions determine neuronal phenotypes in rodent retinal cultures. J Neurobiol 23:1067-1083.

Reh TA (1992b) Generation of neuronal diversity in the vertebrate retina. In: Determinants of neuronal identity (Shankland M, Macagno ER, eds), pp 433-467. New York: Academic.

Reh TA, Cagan RL (1994) Intrinsic and extrinsic signals in the developing vertebrate and fly eyes: viewing vertebrate and invertebrate eyes in the same light. Perspect Dev Neurobiol 2:183-190.

Reh TA, Kljavin IJ (1989) Age of differentiation determines rat retinal germinal cell phenotype: induction of differentiation by dissociation. J Neurosci 9:4179-4189.

Reh TA, Tully T (1986) Regulation of tyrosine hydroxylase containing amacrine cell number in larval frog retina. Dev Biol 114:463-469.

Reh TA, McCabe K, Kelley MW, Bermingham-McDonogh O (1995) Growth factors in the treatment of degenerative retinal disorders. In: Growth factors as drugs for neurological and sensory disorders, CIBA Foundation Symposium 196 (Bock GR, Goode JA, eds), pp 120-134. New York: Wiley.

Riddle RD, Johnson RL, Laufer E, Tabin C (1993) Sonic hedgehog mediates the polarizing activity of the ZPA. Cell 75:1401-1416.

Roelink H, Augsburger A, Heemskerk J, Korzh V, Norlin S, Ruiz-iAltaba A, Tanabe Y, Placzek M, Edlund T, Jessell TM, Dodd J (1994) Floor plate and motor neuron induction by vhh-1, a vertebrate homolog of hedgehog expressed by the notochord. Cell 76:761-775.

Roelink H, Porter JA, Chiang C, Tanabe Y, Chang DT, Beachy PA, Jessell TM (1995) Floor plate and motor neuron induction by different concentrations of the amino-terminal cleavage product of sonic hedgehog autoproteolysis. Cell 81:445-455.

Sparrow JR, Hicks D, Barnstable CJ (1990) Cell commitment and differentiation in explants of embryonic rat neural retina: comparison with the developmental potential of dissociated retina. Dev Brain Res $51: 69-84$.

Spoerri PE, Ulshafer RJ, Ludwig HC, Allen CB, Kelley KC (1988) Photoreceptor cell development in vitro: influence of pigment epithelium conditioned medium on outer segment differentiation. Eur J Cell Biol 46:362-367.

Stone DM, Hynes M, Armanini M, Swanson TA, Gu Q, Johnson RL, Scott MP, Pennica D, Goddard A, Phillips H, Noll M, Hooper JE, de Sauvage F, Rosenthal A (1996) The tumour-suppressor gene patched encodes a candidate receptor for Sonic hedgehog. Nature 384:129-134.

Strutt DI, Wiersdorff V, Mlodzik M (1995) Regulation of furrow progression in the Drosophila eye by cAMP-dependent protein kinase A. Nature 373:705-709.

Tabata T, Kornberg TB (1994) Hedgehog is a signaling protein with a key role in patterning Drosophila imaginal discs. Cell 76:89-102.

Taylor M, Reh TA (1990) Induction of differentiation of rat retinal, germinal, neuroepithelial cells by dbcAMP. J Neurobiol 21:470-481.

Turner DL, Cepko CL (1987) A common progenitor for neurons and glia persists in rat retina late in development. Nature 328:131-136.

Turner EE, Jenne KJ, Rosenfeld MG (1994) Brn-3.2: a Brn-3 related transcription factor with distinctive central nervous system expression and regulation by retinoic acid. Neuron 12:205-218.

Watanabe T, Raff MC (1990) Rod photoreceptor development in-vitro: intrinsic properties of proliferating neuroepithelial cells change as development proceeds in the rat retina. Neuron 4:461-467.

Watanabe T, Raff MC (1992) Diffusible rod-promoting signals in the developing rat retina. Development 114:899-906.

Wetts R, Fraser SE (1988) Multipotent precursors can give rise to all major cell types of the frog retina. Science 239:1142-1145.

Xiang M, Zhou L, Macke JP, Yoshioka T, Hendry SH, Eddy RL, Shows TB, Nathans J (1995) The Brn-3 family of POU-domain factors: primary structure, binding specificity, and expression in subsets of retinal ganglion cells and somatosensory neurons. J Neurosci 7:4762-4785. 